Braz J Med Biol Res, October 2011, Volume 44(10) 1036-1047

doi: 10.1590/S0100-879X2011007500116

\section{The inflammatory stimulus of a natural latex biomembrane improves healing in mice}

T.A.M. Andrade, A. Iyer, P.K. Das, N.T. Foss, S.B. Garcia, J. Coutinho-Netto, A.A. Jordão-Jr. and M.A.C. Frade

The Brazilian Journal of Medical and Biological Research is partially financed by

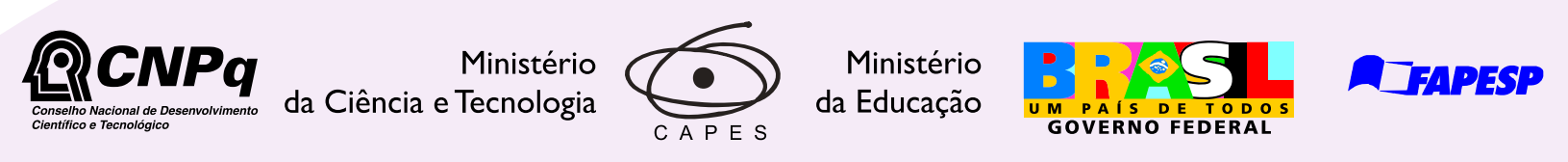

Institutional Sponsors
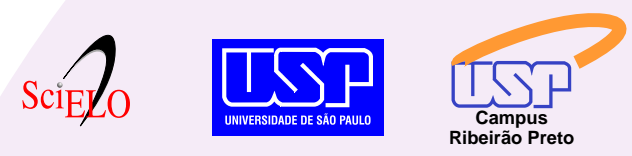

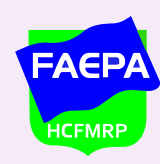

Ф SHIMADZU

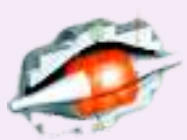

Explore High - Performance MS Orbitrap Technology
In Proteomics \& Metabolomics

$\underset{\text { analitica }}{\text { analiticaweb.com.br }}$ SCIENTIFIC 


\title{
The inflammatory stimulus of a natural latex biomembrane improves healing in mice
}

\author{
T.A.M. Andrade ${ }^{1}$, A. Iyer ${ }^{5}$, P.K. Das ${ }^{5}$, N.T. Foss ${ }^{1}$, S.B. Garcia ${ }^{3}$, J. Coutinho-Netto ${ }^{4}$, \\ A.A. Jordão-Jr. ${ }^{2}$ and M.A.C. Frade ${ }^{1,5}$ \\ ${ }^{1}$ Divisão de Dermatologia, ${ }^{2}$ Divisão de Nutrição e Metabolismo, Departamento de Clínica Médica, \\ ${ }^{3}$ Departamento de Patologia, ${ }^{4}$ Departamento de Bioquímica e Imunologia, \\ Faculdade de Medicina de Ribeirão Preto, Universidade de São Paulo, Ribeirão Preto, SP, Brasil \\ ${ }^{5}$ Department of Pathology, Academic Medical Center, University of Amsterdam, Amsterdam, The Netherlands
}

\begin{abstract}
The aim of the present study was to compare healing obtained with biomembranes with the natural healing process (sham) using biochemical and immunohistological assays. C57BL/6 mice were divided into 4 groups of 15 mice each and received different subcutaneous implants: natural latex biomembrane (NLB), denatured latex (DL), expanded polytetrafluorethylene (ePTFE), or sham. On the 2nd, 7th, and 14th days post-treatment, 5 mice per group were sacrificed and biopsied for the following measurements: oxidative stress based on malondialdehyde (MDA), myeloperoxidase (MPO) and hydrogen peroxide by the method of ferrous oxidation-xylenol orange (FOX), as well as glutathione and total proteins; histological evaluation to enumerate inflammatory cells, fibroblasts, blood vessels, and collagen, and immunohistochemical staining for inducible nitric oxide synthase, interleukin-1 $\beta$, vascular endothelial growth factor (VEGF), and transforming growth factor- $\beta 1$ (TGF- $\beta 1$ ). On day 2 post-treatment, NLB stimulated a dense inflammatory infiltrate mainly consisting of polymorphonuclear cells, as indicated by increased MPO $(P<0.05)$, but oxidative stress due to MDA was not observed until the 7 th day $(P<0.05)$. The number of blood vessels was greater in NLB $(P<0.05)$ and $D L(P<0.05)$ mice compared to sham animals on day 14 . NLB induced fibroplasia by day $14(P<0.05)$ with low expression of TGF- $\beta 1$ and collagenesis. Thus, NLB significantly induced the inflammatory phase of healing mediated by oxidative stress, which appeared to influence the subsequent phases such as angiogenesis (with low expression of VEGF) and fibroplasia (independent of TGF- $\beta 1$ ) without influencing collagenesis.
\end{abstract}

Key words: Wound healing; Inflammation; Oxidative stress; Angiogenesis; Latex; Histomorphometry

\section{Introduction}

Wound healing is a dynamic process that is directed towards restoring the structure of the injured tissue. The process begins immediately after the injury with the release of platelet granules, important in the clotting cascade. Simultaneously, cytokines and growth factors are released, which are important in the recruitment of inflammatory cells to the site of injury. These processes are essential for local debridement (inflammatory phase), the formation of granulation tissue (angiogenesis), followed by proliferation of fibroblasts, formation of extracellular matrix and collagen, reepithelialization, and finally tissue remodeling $(1,2)$.

The wound healing phases have been strongly associated with oxidative stress. Reactive oxygen species (ROS) and reactive nitrogen species (RNS) have a significant role in potentiating the inflammatory phase with a direct effect on platelet recruitment and activation besides neu- trophil chemotaxis. Macrophages have an important role in generating inflammation and the respiratory burst. ROS also help in the reepithelialization of wounds by activating collagenase expression and mediate epidermal growth factor signaling (3).

Earlier studies have assessed several biomaterials as stimulators of the wound healing process $(4,5)$. Most studies involving biomaterials have been done using subcutaneous implants in animal models, and have shown that this can be an appropriate model for evaluating immunological and tissue modifications due to the implants during the wound healing process (6). Among biomaterials, the biocompatible (7) natural latex biomembrane (NLB), derived from the rubber tree Hevea brasiliensis, has been shown to accelerate the wound healing process in humans (8-11) and animal $(12-14)$ models.

Correspondence: M.A.C. Frade, Divisão de Dermatologia, Faculdade de Medicina de Ribeirão Preto, USP, Av. Bandeirantes, 3900, 14048-900 Ribeirão Preto, SP, Brasil. Fax: +55-16-3633-0236. E-mail: mandrey@fmrp.usp.br

Received July 19, 2010. Accepted August 22, 2011. Available online September 9, 2011. Published October 10, 2011. 
Mrué et al. (7) evaluated the biocompatibility of NLB using an in vivo assay in different animal species. Subcutaneous implantation of the NLB in the ventral wall of dogs showed recovery of the host tissue without any sign of fibrosis or rejection. The effect of NLB was studied in a dermal ulcer model in the rabbit ear and showed improved tissue repair comparable to normal physiological healing. These results demonstrated that NLB is indeed a biocompatible material.

NLB was effectively used in reconstruction of the pericardium of dogs (15), in iatrogenic defects in the abdominal wall of rats (16), and induced neo-angiogenesis in rabbit corneas (12). Balabanian et al. (13) implanted a granule of latex into the bone alveolar cavity of rats after extraction of the upper right incisor. A progressive integration of the latex into the alveolar bone and acceleration of bone formation was observed, which played an important role in the healing process. Domingos et al. (14) have demonstrated that the NLB is biocompatible and can be used in models for bladder augmentation in rabbits. This biomaterial allows a progressive ingrowth of all components of the bladder wall, promoting epithelium and muscle regeneration without postoperative urinary leakage and with a low rate of stone formation.

No evidence of toxicity or of an allergic reaction was found when the NLB was used to reconstruct the tympanic membrane of rabbits and in human venous ulcers $(8,17)$. However, the allergenic potential of ultra-vulcanized latex has been well established in latex glove users and in other high-risk groups of patients with different types of latex exposure (18).

Studies carried out in humans showed that NLB was effective in healing of skin ulcers, especially in diabetic patients (9), and of chronic venous ulcers $(10,19)$ and pressure ulcers (11).

Studies conducted by Mrué et al. (7) and Frade et al. $(9,17)$ have emphasized the direct angiogenic activity of latex, a property attributed to a vascular growth factor. However, the actual mechanism of action of latex regarding its role in the inflammatory phase and consequent angiogenic action is still unclear.

Considering the glycoprotein composition of latex (20) used to manufacture the NLB, in contrast to denatured latex (DL), where protein is inactivated by high temperature, and the standard biocompatible synthetic implant expanded polytetrafluorethylene (ePTFE), the present study was carried out to compare the immunobiological mechanisms and the oxidative stress status involved in tissue healing stimulated with these membranes to those of natural healing in the absence of any treatment (sham).

\section{Material and Methods}

\section{Animals \\ Sixty C57BL/6 male mice with a mean weight of 25.0}

$\mathrm{g}$ (range: 20.0 to $25.0 \mathrm{~g}$ ), aged 8 to 10 weeks were maintained at the animal facilities of the Departamento de Clínica Médica, Faculdade de Medicina de Ribeirão Preto, Universidade de São Paulo, in accordance with the ethical guidelines of the Brazilian College of Animal Experimentation (COBEA) (protocol No. 055/2005).

The mice were randomly assigned to 4 groups of 15 animals each depending on the type of implant as described below: NLB, DL, ePTFE, or no implant (sham).

\section{Biomaterials}

Natural latex biomembrane (NLB). This membrane is made of natural latex extracted from the rubber tree, $H$. brasiliensis. The natural latex was placed on a Petri dish and warmed at $60^{\circ} \mathrm{C}$ in a stove (Olidef CZ, Brazil) for polymerization. The product was then sterilized with ethylene oxide and implanted in animals (7-16).

Denatured latex (DL). A sterile, surgical type, latexbased glove without talc (Supermax, Brazil) was used as an implant in this group of mice. This material was used to evaluate the property of latex containing no active protein, which was denatured by high temperature $\left(130-150^{\circ} \mathrm{C}\right)$ during the latex vulcanization to manufacture gloves.

Expanded polytetrafluorethylene (ePTFE). Commercial sterilized membranes (Surgitime PTFE rectangle; Bionnovation Biomedical, USA) were purchased ready for use.

\section{Surgical procedure}

The animals were anesthetized with an intraperitoneal injection of a $2.5 \%$ solution of tri-bromoethanol $(100 \mu \mathrm{L} / 10$ g; Sigma, USA). A dorsal linear skin incision $(0.5 \mathrm{~cm})$ was performed for the subcutaneous implantation of the different biomaterials $\left(1.0 \mathrm{~cm}^{2}\right)$. The incisions were then sutured with mononylon 5-0 (PolySuture, Brazil). The sham group (control) underwent the same surgical procedure as the treated groups but did not receive any implant.

\section{Harvesting of the material for study}

Five animals from each group were sacrificed on the 2nd, 7th, and 14th days post-implanting with an overdose of anesthetic. The entire dorsal skin of the mouse, including the implant and muscle, was excised. Four-millimeter punch biopsies were taken for the study of oxidative stress based on malondialdehyde (MDA) and myeloperoxidase (MPO) levels, for the determination of lipid hydroperoxides by ferrous ion oxidation-xylenol orange (FOX), glutathione (GSH), and total protein assays and for histological studies [hematoxylin-eosin (HE) and Gomory's trichrome staining] and immunohistochemistry [interleukin-1 $\beta$ (IL-1 $\beta$ ), inducible nitric oxide synthase (iNOS), vascular endothelial growth factors (VEGF), and transforming growth factor- $\beta 1$ (TGF- $\beta 1)$ ].

The biopsies were collected into ice-cold $1.15 \% \mathrm{KCl}$ solution for the MDA assay, into ice-cold buffer $(0.1 \mathrm{M} \mathrm{NaCl}$, $20 \mathrm{mM} \mathrm{NaPO}_{4}, 15 \mathrm{mM} \mathrm{NaEDTA}, \mathrm{pH}$ 4.7) for the MPO as- 
say, into ice-cold $20 \mathrm{mM}$ EDTA buffer for the GSH assay, and into ice-cold Milli-q water for the total protein and FOX assays. All were stored at $-80^{\circ} \mathrm{C}$ until use. The biopsies for histology and immunohistochemistry were fixed in $10 \%$ buffered paraformaldehyde and embedded in paraffin.

\section{Oxidative stress assays}

Malondialdehyde assay. Oxidative stress parameters were assessed by analysis of thiobarbituric acid reactive substances (TBARS), which represents the rate of lipid peroxidation determined by the method of Buege and Aust (21) and quantified using the molar extinction coefficient $\varepsilon=$ $1.56 \times 10^{5} \cdot \mathrm{cm}^{-1} \cdot \mathrm{M}^{-1}$. Samples of $100 \mu \mathrm{L}$ tissue homogenates from all groups were deproteinized with $20 \%$ trichloroacetic acid, gently shaken for $30 \mathrm{~min}$ and centrifuged at 5000 g. The supernatant was exposed to $0.7 \%$ thiobarbituric acid and heated to $95^{\circ} \mathrm{C}$ for $45 \mathrm{~min}$ and, after cooling, absorbance was read at $535 \mathrm{~nm}$ with a Spectra Max 250 spectrophotometer (Molecular Devices, USA) (22). Results are reported as $\mu \mathrm{mol} \mathrm{MDA} / \mathrm{g}$ tissue.

Myeloperoxidase assay. The accumulation of polymorphonuclear cells (PMNs) in tissues was measured by the MPO assay as described by Souza et al. (23). Briefly, the biopsy was weighed and homogenized using a Polytron ${ }^{\circledR}$ PT 3100 (5000 g) homogenizer (Kinematica, Inc., USA). The pellet was lysed with $15 \mathrm{~mL} 0.2 \% \mathrm{NaCl}$ solution for $30 \mathrm{~s}$ followed by the addition of $1.6 \% \mathrm{NaCl}$ containing $5 \%$ glucose. After centrifugation, the pellet was resuspended in $0.05 \mathrm{M} \mathrm{NaPO}_{4}$ buffer, pH 5.4, containing $0.5 \%$ hexadecyltrimethylammonium bromide and re-homogenized. Aliquots of $1.0 \mathrm{~mL}$ of the suspension were transferred to Eppendorf tubes followed by 3 cycles of freezing-thawing using liquid nitrogen. The aliquots were centrifuged for 15 min at $5000 \mathrm{~g}$ and $5.0 \mu \mathrm{L}$ of the supernatant diluted in 45.0 $\mu \mathrm{L} 0.08 \mathrm{M} \mathrm{NaPO}_{4}$ was used for the assay in 96-well plates. MPO activity in the supernatant was detected using $25 \mu \mathrm{L}$ $1.6 \mathrm{mM}$ tetramethylbenzidine (Sigma) followed by $100 \mu \mathrm{L}$ $0.5 \mathrm{mM} \mathrm{H}_{2} \mathrm{O}_{2}$. Absorbance was measured with a 96-well plate reader at $450 \mathrm{~nm}$. The results were reported as the total number of PMN cells $\times 10^{3} / \mathrm{mg}$ tissue by comparing the absorbance of the tissue supernatant to a standard curve generated using mouse peritoneal neutrophils induced by $5 \%$ casein and processed in the same way.

Lipid peroxidation assay - FOX assay. This assay is used for the quantitative determination of the low levels of lipid hydroperoxide in the samples. It is based on the oxidation of ferrous ions $\left(\mathrm{Fe}^{2+}\right)$ to ferric ions $\left(\mathrm{Fe}^{3+}\right)$ by hydrogen peroxide under acidic conditions. Briefly, $900 \mu \mathrm{L}$ FOX reagent $(49 \mathrm{mg}$ ferrous ammonium sulfate in $50 \mathrm{~mL}$ $250 \mathrm{mM} \mathrm{H}_{2} \mathrm{SO}_{4}, 0.397 \mathrm{~g} \mathrm{BHT}$, and $0.038 \mathrm{~g}$ xylenol orange in $950 \mathrm{~mL}$ ) was added to the samples. The ferric ion binds to the indicator dye xylenol orange to form a stable colored complex, which can be measured at $560 \mathrm{~nm}$ as an indirect measure of hydroperoxide concentration. Results are reported as $\mu \mathrm{mol} \mathrm{H}_{2} \mathrm{O}_{2} / \mathrm{g}$ tissue (24).
Glutathione assay. GSH concentrations (non-protein small thiols) in tissue samples were determined by the method of Sedlak and Lindsay (25) with Ellman's reagent (dithionitrobenzoic acid), at a wavelength of $412 \mathrm{~nm}$, using $\varepsilon=14.1 \mathrm{mM}^{-1} \mathrm{~cm}^{-1}$. Results are reported as $\mu \mathrm{mol} \mathrm{GSH} / \mathrm{g}$ tissue.

Total protein assay. Total protein was determined by the biuret test using an enzymatic kit (LABTEST ${ }^{\circledR}$, Brazil). Results are reported as $\mathrm{g}$ total protein/g tissue.

\section{Histology}

Five-micrometer thick paraffin sections were stained with $\mathrm{HE}$ to evaluate the inflammatory infiltrate and angiogenic and fibroblastic responses and with Gomory's trichrome staining for collagenesis.

Evaluation of inflammatory infiltrate, angiogenesis and fibroplasia by image analysis. The sections were photographed at $400 \mathrm{X}$ with a Leica ${ }^{\circledR}$ DM $4000 \mathrm{~B}$ microscope equipped with a Leica ${ }^{\circledR}$ DFC 280 camera (Leica Microsystems, Germany). The images were captured using the Leica Application Suite ${ }^{\circledR}$ Version 3.2.0 software. Ten different fields ( 5 from the superficial dermis, 2 from the deep dermis, and 3 from a neo-tissue area) were examined and a region of interest (ROI) of $900 \times 300$ pixels was acquired for each field. The ImageJ 1.36 software (U.S. National Institutes of Health, USA) $(26,27)$ was used to count the inflammatory cells, fibroblasts and blood vessels in each field. Five different mice were used for each treatment at each time $(\mathrm{N}=5)$ and the data are reported as the average number of inflammatory cells, fibroblasts and blood vessels per group (28).

Evaluation of collagenesis by imaging. Collagenesis, as seen in Gomory's trichrome-stained slides, was measured as follows: 10 different fields were photographed at 100X and a ROI of $320 \times 40$ pixels $(=2.62 \times 0.33 \mu \mathrm{m}$, converted using ImageJ) was selected for each field. The distribution of blue color (collagen) was quantified as a percentage of the total number of pixels in the ROI using the "Threshold color" plug-in of the ImageJ software. Five different mice were used for each treatment at each time $(\mathrm{N}=5)$ and the final results are reported as the average distribution of collagen per treatment (28).

\section{Immunohistochemistry}

Five-micrometer paraffin sections were subjected to antigen retrieval by autoclaving in citrate buffer, $\mathrm{pH} 6.0$, for $5 \mathrm{~min}$. Endogenous peroxidase was blocked with $3 \%$ hydrogen peroxide in PBS followed by nonspecific blocking with $1 \%$ BSA. The sections were incubated with the primary antibody in $1 \%$ BSA overnight at $4^{\circ} \mathrm{C}$. The antibodies used were rabbit anti-mouse IL-1 $\beta \lg$ (1:100), NOS2 rabbit anti-mouse IgG (1:200), rabbit anti-mouse VEGF IgG (1:100), and rabbit anti-mouse TGF- $\beta 1 \operatorname{lgG}(1: 150)$ all from Santa Cruz Biotechnology (USA). The sections were then incubated with biotinylated goat anti-rabbit $\lg \mathrm{G}(\mathrm{H}+\mathrm{L})$ as 
the secondary antibody followed by the Vectastain $A B C^{\circledR}$ Kit (Vector, USA). The color reaction was developed using 3,3 diaminobenzidine tetrahydrochoride (Sigma-Aldrich, Germany). The sections were counterstained with Mayer's hematoxylin and mounted in Entellan (Sigma-Aldrich).

\section{Statistical analysis}

Analysis of variance for multiple comparisons (one-way ANOVAand the Tukey test) was used for statistical analysis. The results were compared among groups on the same day of follow-up, and among days for each group. A P value $<0.05$ at a confidence interval of $95 \%$ was considered to be statistically significant.

\section{Results}

\section{Oxidative stress status in neoformed tissue}

On day 2, the NLB group showed significant recruitment of PMN cells compared to the other groups $(P<0.01)$. A significant decrease was observed in inflammatory activity in the NLB group in terms of infiltration and MPO assay on days 7 and 14 compared to day 2 $(P<0.01)$. Nevertheless, on day 7 , all 3 implants showed significantly higher MPO activity compared to the sham group $(P<0.01)$, although no difference was observed among the different implants. On day 14, NLB and DL maintained significantly higher MPO values as compared to the ePTFE and sham groups $(P<0.01$; Table 1$)$.

The level of MDA in the ePTFE group was high compared to the other groups on day 2 but with no statistically significant difference. MDA levels in the ePTFE group declined significantly on day $7(P<0.05)$. On the other hand, NLB, with low levels of MDA on day 2 , showed a significant increase only on day $7(P<0.05)$, besides showing higher MDA levels compared to the DL and ePTFE groups ( $P<0.05)$. No significant difference was observed in MDA levels between the NLB and sham treatments on days 2 and 7 . However, on day 14 this difference was statistically significant $(P<0.05)$. The DL group presented low MDA levels on days 2 and 7 although it was similar to NLB on day 14 (Table 1).

The NLB group showed similar and low peroxidative activity on all days of follow-up in the FOX assay. All other groups presented higher
FOX levels compared to NLB $(P<0.05)$. The sham group showed a higher FOX value on day 2 compared to days 7 and $14(\mathrm{P}<0.05$; Table 1$)$.

The sham group showed a higher GSH level on day 2 compared to days 7 and 14, although the difference was not statistically significant. The ePTFE group showed reduction of GSH from day 2 to day 7 ( $P<0.05)$. On day 7 , the $D L$ group showed high GSH levels compared to other groups $(P$ $>0.05$ ). On day 14, all implanted groups presented similar GSH levels (Table 1).

With respect to total protein, on day 2, the NLB group showed significantly higher levels compared to the other groups and a significant reduction during follow-up $(P<0.05$; Table 1). On day 7, the sham and ePTFE groups presented higher total protein levels, although without statistical difference. On day 14, the DL group presented higher total protein levels $(P>0.05)$. These findings can be related to the larger amount of neoformed tissue induced by NLB compared to the other groups, followed by considerable
Table 1. Oxidative stress status of cutaneous biopsies during follow-up.

\begin{tabular}{|c|c|c|c|}
\hline & 2nd day & 7th day & 14th day \\
\hline \multicolumn{4}{|c|}{ MPO (PMN cells $\times 10^{3} / \mathrm{mg}$ tissue) } \\
\hline NLB & $18.05 \pm 2.21^{*+}$ & $5.58 \pm 3.85^{*}$ & $2.92 \pm 2.86^{*}$ \\
\hline DL & $5.58 \pm 4.32$ & $5.12 \pm 3.41^{*}$ & $1.92 \pm 0.84^{*}$ \\
\hline ePTFE & $4.31 \pm 1.85^{+}$ & $3.87 \pm 2.85^{\star}$ & $0.89 \pm 0.22$ \\
\hline Sham & $4.96 \pm 7.61^{+}$ & $0.41 \pm 0.14$ & $1.04 \pm 0.44$ \\
\hline \multicolumn{4}{|c|}{ MDA ( $\mu \mathrm{mol}$ MDA/g tissue) } \\
\hline NLB & $0.04 \pm 0.03$ & $0.31 \pm 0.21^{*+}$ & $0.10 \pm 0.12$ \\
\hline $\mathrm{DL}$ & $0.05 \pm 0.02$ & $0.07 \pm 0.01$ & $0.09 \pm 0.11$ \\
\hline ePTFE & $0.16 \pm 0.20^{+}$ & $0.03 \pm 0.01$ & $0.05 \pm 0.02$ \\
\hline Sham & $0.05 \pm 0.03$ & $0.14 \pm 0.09^{+}$ & $0.04 \pm 0.01$ \\
\hline \multicolumn{4}{|c|}{ FOX ( $\mu \mathrm{mol} \mathrm{H}_{2} \mathrm{O}_{2} / \mathrm{g}$ tissue $)$} \\
\hline NLB & $0.33 \pm 0.15$ & $0.32 \pm 0.25$ & $0.20 \pm 0.22$ \\
\hline DL & $0.57 \pm 0.38$ & $0.55 \pm 0.26$ & $0.57 \pm 0.31^{*}$ \\
\hline ePTFE & $0.60 \pm 0.42$ & $0.42 \pm 0.17$ & $0.67 \pm 0.34^{*}$ \\
\hline Sham & $0.83 \pm 0.35^{\star+}$ & $0.45 \pm 0.32$ & $0.53 \pm 0.22^{*}$ \\
\hline \multicolumn{4}{|c|}{ GSH ( $\mu \mathrm{mol}$ GSH/g tissue) } \\
\hline NLB & $4.00 \pm 1.49$ & $4.44 \pm 1.56$ & $5.84 \pm 0.87$ \\
\hline DL & $5.82 \pm 1.64$ & $10.08 \pm 3.47$ & $5.64 \pm 2.79$ \\
\hline ePTFE & $6.85 \pm 1.52^{+}$ & $4.37 \pm 0.99$ & $6.65 \pm 1.73$ \\
\hline Sham & $7.98 \pm 0.53$ & $5.23 \pm 2.36$ & $3.85 \pm 0.29$ \\
\hline \multicolumn{4}{|c|}{ Total protein (g total protein/g tissue) } \\
\hline NLB & $0.38 \pm 0.15^{*+}$ & $0.26 \pm 0.04$ & $0.26 \pm 0.05$ \\
\hline $\mathrm{DL}$ & $0.27 \pm 0.10$ & $0.19 \pm 0.04$ & $0.33 \pm 0.23$ \\
\hline ePTFE & $0.26 \pm 0.04$ & $0.37 \pm 0.08$ & $0.30 \pm 0.07$ \\
\hline Sham & $0.24 \pm 0.05$ & $0.42 \pm 0.21$ & $0.31 \pm 0.09$ \\
\hline
\end{tabular}

Myeloperoxidase (MPO), malondyaldehyde (MDA), $\mathrm{H}_{2} \mathrm{O}_{2}$ by ferrous oxidation-xylenol orange (FOX) method, glutathione (GSH), and total protein assay on the $2 \mathrm{nd}$, 7 th, and 14th days. $\mathrm{PMN}=$ polymorphonuclear cells; NLB = natural latex biomembrane; $\mathrm{DL}=$ denatured latex; ePTFE = expanded polytetrafluorethylene; Sham = without implant. ${ }^{*} \mathrm{P}<$ 0.05 between groups; ${ }^{+} \mathrm{P}<0.05$ between days (one-way ANOVA and Tukey test). 
reduction of tissue during follow-up (Figure 1).

\section{Inflammatory phase of wound healing}

All three implants studied induced greater numbers of infiltrating cells compared to the sham group. Although the DL group showed a greater inflammatory infiltrate than the ePTFE and sham groups, the NLB-implanted group presented the most pronounced inflammatory reaction compared to all other groups. The infiltrate showed a predominance of PMN cells, even in deeper layers of the skin (Figure 2A-D), as measured by the MPO assay (Table 1 ).

On day 2 post-implant, NLB induced significantly higher numbers of inflammatory cells compared to the DL, ePTFE and sham groups $(P<0.05)$. However, no significant difference was observed between the DL, ePTFE and sham groups. Moreover, all implants showed a statistically significant reduction of the inflammatory infiltrate from day 2 to day $7(P<0.05)$, but this reduction was more pronounced in the NLB group $(P<0.05$; Table 2$)$.

On day 7 , the ePTFE group showed a lower inflammatory infiltrate compared to the other groups $(P<0.05)$ while the $D L$ group had a higher inflammatory infiltrate compared to the sham group. The DL, ePTFE and sham groups showed a statistically significant reduction of the inflammatory infiltrate from day 7 to day 14 ( $P$ $<0.05$ ) and the NLB group showed a reduction without statistical difference (Table 2).

The NLB and sham groups showed a significantly higher inflammatory cell count compared to ePTFE on day 14. However, no significant difference was observed in inflammatory cell counts between the NLB, DL and sham groups (Table 2).

Qualitative assessment by immunohistochemistry on day 2 showed higher intracellular production of IL-1 $\beta$ in the NLB group compared to the DL and ePTFE groups. However, no difference was observed between the NLB and sham groups (Figure 3A-D). Both NLB and ePTFE showed low expression of iNOS compared to the DL and sham groups (Figure 3E-H).

\section{Angiogenesis}

The NLB group presented increased numbers of neo-vessels on day 7 compared to the other treatments and the sham group. Although more vascular neoformation was observed in the DL group than in the ePTFE and sham groups, it was lower than that observed in the NLB group (Figure 4A-D). The formation of blood vessels in the NLB and DL groups seemed to remain stable on day 14 compared to day 7 , and remained higher in all groups compared to sham on day 14 .
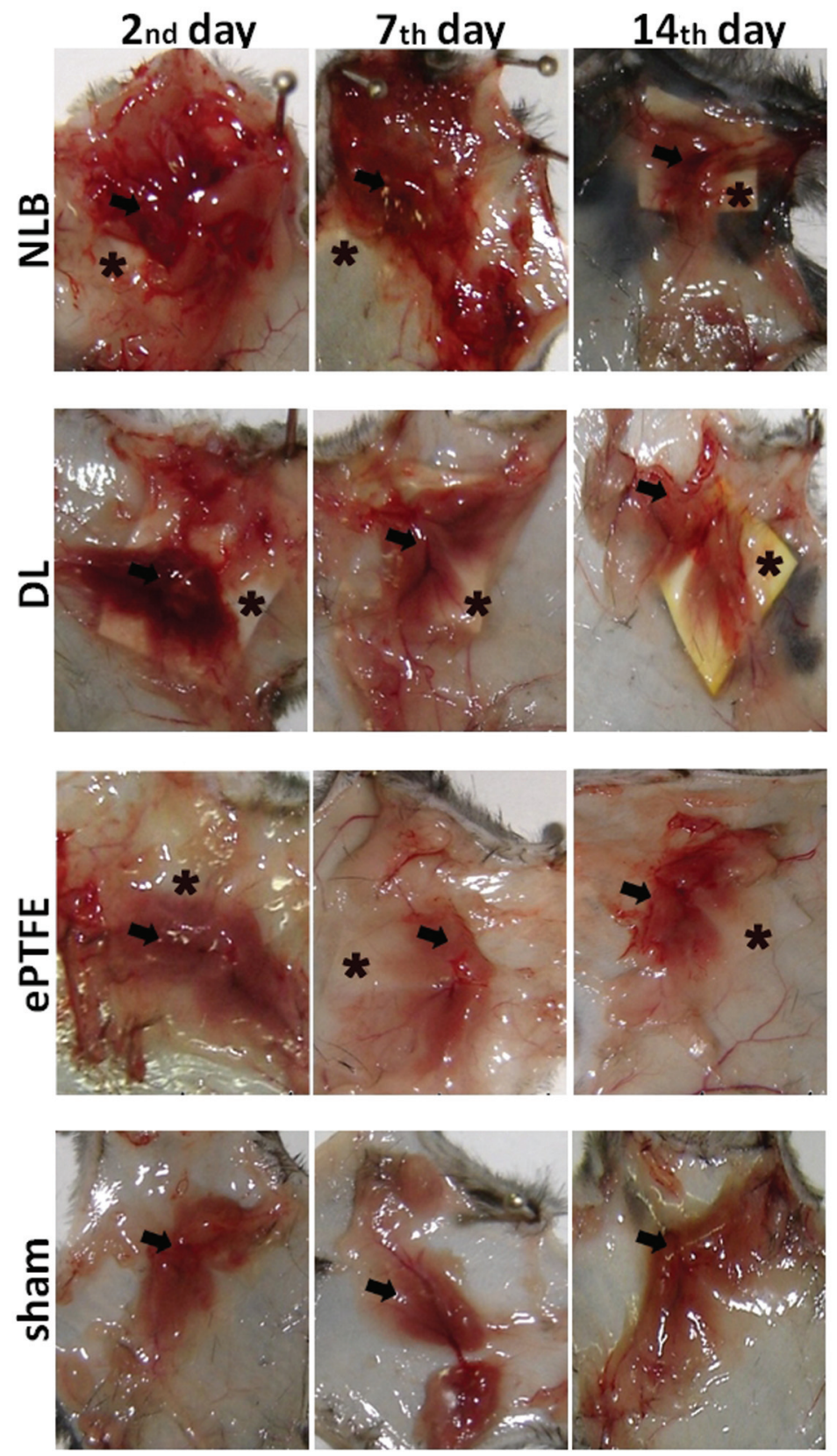

Figure 1. Macroscopic difference of neoformed tissue on the back of mice (arrows) induced by subcutaneously implanted biomaterial (asterisks) on the 2nd, 7th, and 14th days. NLB = natural latex biomembrane; DL = denatured latex; ePTFE = expanded polytetrafluorethylene; sham $=$ without implant. The NLB group showed a greater amount of neoformed tissue on day $2 \mathrm{com}-$ pared to the other groups and an important reduction of tissue quantity was observed during follow-up. 

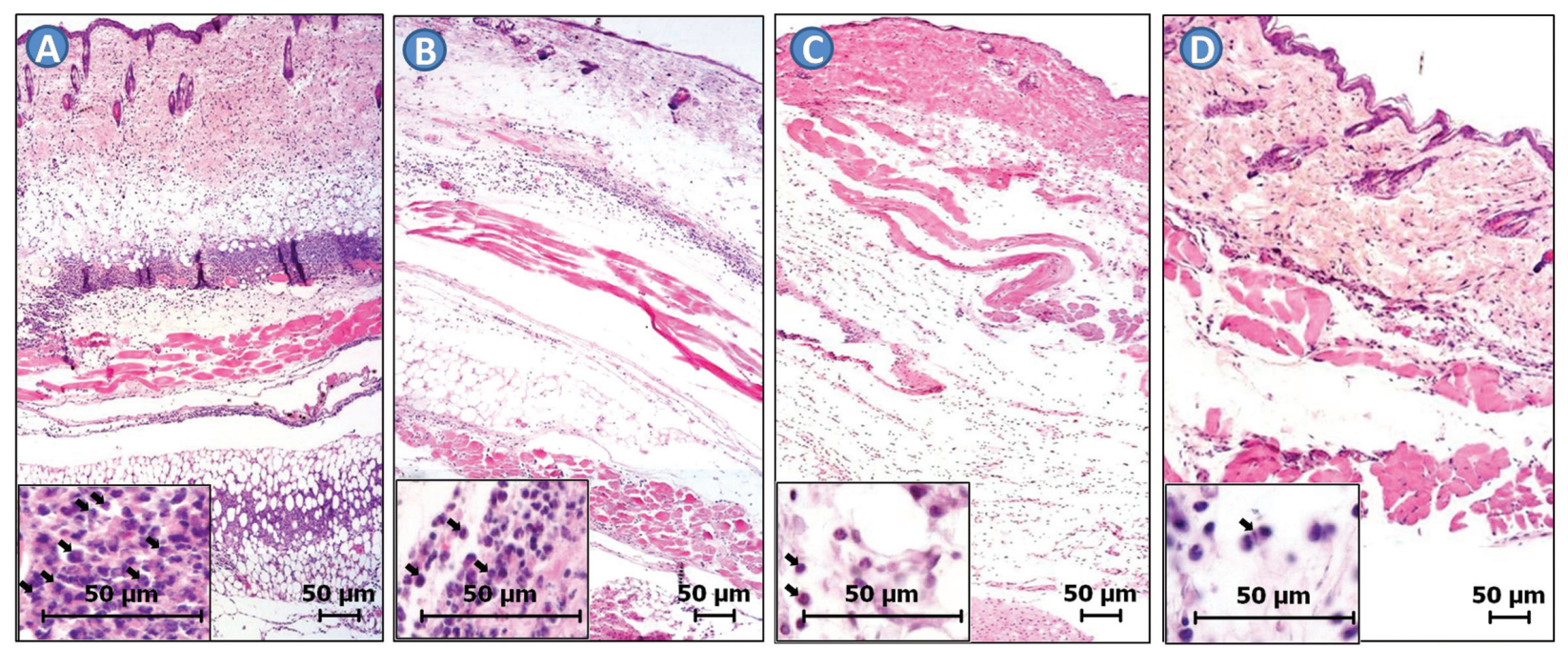

Figure 2. Hematoxylin-eosin staining of skin and subcutaneous tissue showing the inflammatory infiltrate (arrows) in groups NLB $(A)$, DL $(B)$, ePTFE $(C)$, and sham $(D)$ on the 2 nd day of follow-up. Bar $=50 \mu \mathrm{m}$ (magnification: 100 and $400 X$ ). NLB $=$ natural latex biomembrane; $\mathrm{DL}$ = denatured latex; ePTFE = expanded polytetrafluorethylene; sham = without implant. The NLB group showed a more pronounced inflammatory infiltrate compared to the other implants on day 2 . In contrast to the other implants the inflammatory infiltrate predominantly consisted of polymorphonuclear cells reaching deep layers of the skin.

Table 2. Quantitative analysis of histological parameters of cutaneous biopsies during follow-up.

\begin{tabular}{lccc}
\hline & 2nd day & 7 th day & 14th day \\
\hline Inflammatory infiltrate (number of cells) & & & \\
NLB & $97.73 \pm 35.66^{*+}$ & $25.83 \pm 3.67^{*}$ & $3.70 \pm 1.71^{*}$ \\
DL & $46.23 \pm 5.82^{+}$ & $32.20 \pm 7.08^{*+}$ & $1.97 \pm 1.26$ \\
ePTFE & $33.90 \pm 11.05^{+}$ & $13.33 \pm 4.08^{+}$ & $1.20 \pm 0.82$ \\
Sham & $25.23 \pm 11.89^{+}$ & $21.97 \pm 4.05^{*+}$ & $3.17 \pm 1.20^{*}$ \\
Angiogenesis (number of blood vessels) & & & \\
NLB & $0.27 \pm 0.31$ & $1.50 \pm 1.40^{*}$ & $1.73 \pm 0.85^{\star+}$ \\
DL & $0.13 \pm 0.06$ & $1.80 \pm 0.95^{*+}$ & $1.47 \pm 0.32^{*+}$ \\
ePTFE & $0.30 \pm 0.26$ & $0.53 \pm 0.21$ & $0.50 \pm 0.36$ \\
Sham & $0.33 \pm 0.58$ & $0.03 \pm 0.06$ & $0.07 \pm 0.12$ \\
Fibroplasia (number of fibroblasts) & & & \\
NLB & $2.33 \pm 2.41$ & $22.30 \pm 4.20^{*+}$ & $55.67 \pm 13.85^{*+}$ \\
DL & $1.53 \pm 0.85$ & $21.17 \pm 3.70^{*+}$ & $40.47 \pm 2.45^{*+}$ \\
ePTFE & $2.27 \pm 0.75$ & $45.90 \pm 17.39^{*+}$ & $29.43 \pm 8.21^{+}$ \\
Sham & $2.67 \pm 0.91$ & $4.80 \pm 2.43$ & $30.03 \pm 13.18^{+}$ \\
Collagenesis (\% of collagen area) & & & \\
NLB & $43.82 \pm 9.30^{+}$ & $47.41 \pm 7.44$ & $42.72 \pm 6.95$ \\
DL & $46.49 \pm 19.65^{+}$ & $43.84 \pm 5.40$ & $40.72 \pm 4.10$ \\
ePTFE & $40.30 \pm 3.11$ & $50.96 \pm 9.03^{*}$ & $63.81 \pm 11.19^{*}$ \\
Sham & $43.75 \pm 6.47$ & $52.42 \pm 10.78^{*}$ & $55.91 \pm 7.77^{*}$ \\
\hline
\end{tabular}

Inflammatory infiltrate, blood vessels, and fibroblasts were counted with the ImageJ "Cell Counter" and percentage of collagen was determined with the ImageJ "Threshold" on the 2nd, 7th, and 14th days of follow-up. NLB = natural latex biomembrane; $\mathrm{DL}=$ denatured latex; ePTFE = expanded polytetrafluorethylene; Sham $=$ without implant. ${ }^{*} P<0.05$ between groups; ${ }^{+} P<0.05$ between days (one-way ANOVA and Tukey test). 
All groups presented low numbers of blood vessels on day 2; however, the NLB $(P>0.05)$ and $D L(P<0.05)$ groups showed a significant improvement of vascular neoformation on day 7 and day 14 compared to the ePTFE and sham groups. On day 7, the NLB and DL groups showed higher numbers of blood vessels compared to the ePTFE and sham groups $(\mathrm{P}<$ 0.05). On day 14 , this improvement of vascular neoformation was more pronounced especially in the NLB and DL groups $(\mathrm{P}<0.05)$, which showed more vascular neoformation on day 14 compared to the ePTFE and sham groups.

All groups showed positive staining for VEGF on day 7 (Figure 5A-D), which persisted in the NLB, ePTFE and sham groups on day 14 , while decreased staining was observed only in the DL group (Figure 5E-H).
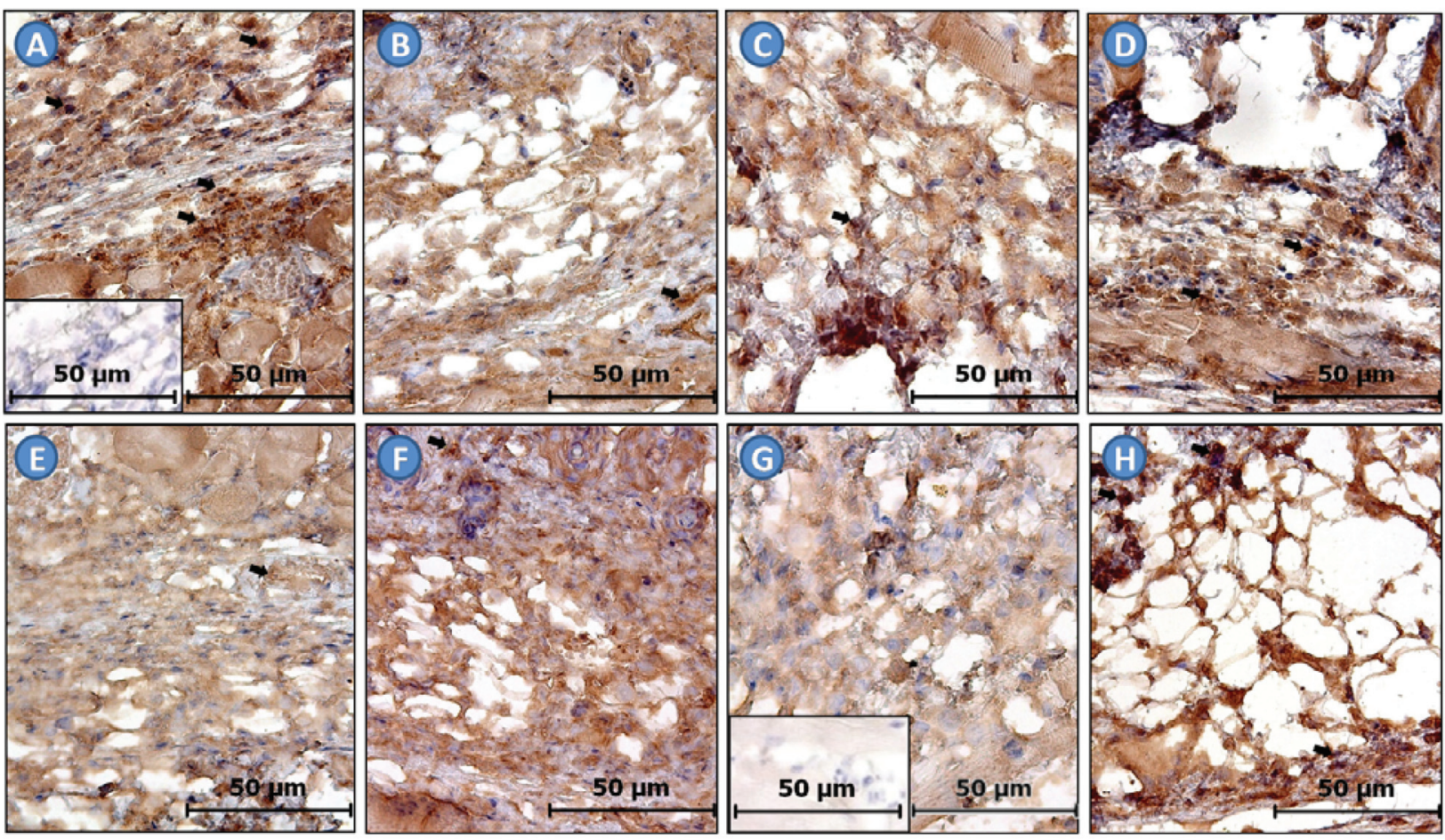

Figure 3. Immunohistochemical staining for interleukin-1 $\beta$ (IL-1 $\beta, A-D$, arrows) on the 2 nd day of implantation and inducible nitric oxide synthase (iNOS, $E-H$, arrows) in groups NLB $(A / E)$, DL $(B / F)$, ePTFE $(C / G)$, and sham $(D / H)$. Detail: negative control. Bar $=50$ $\mu \mathrm{m}$ (400X magnification). NLB = natural latex biomembrane; $\mathrm{DL}=$ denatured latex; ePTFE = expanded polytetrafluorethylene; sham = without implant. The NLB group showed more staining for IL-1 $\beta$ on day 2 compared to the other groups. Both the NLB and ePTFE groups showed low expression of iNOS compared to the DL and sham groups.
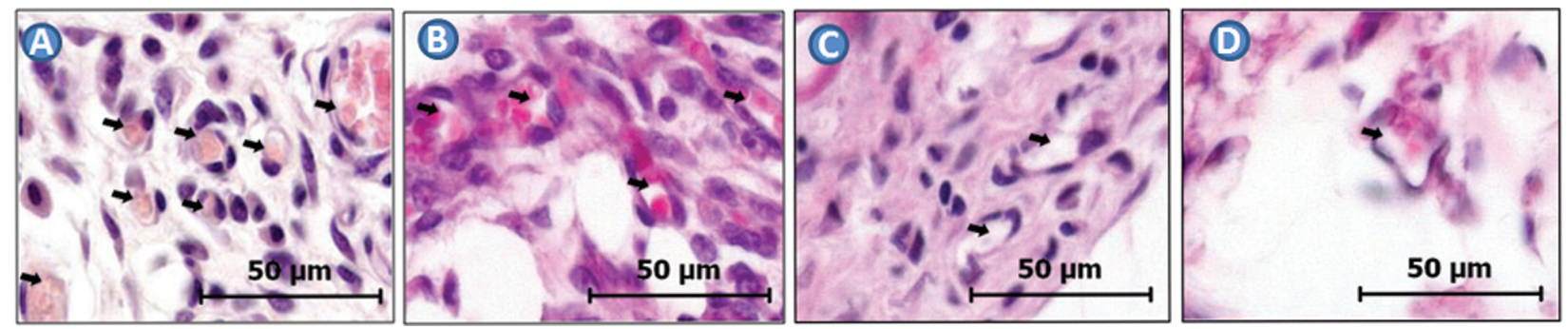

Figure 4. Histological alterations (HE) showing angiogenesis in groups NLB $(A)$, DL $(B)$, ePTFE $(C)$, and sham $(D)$ on the 7th day of follow-up. Bar $=50 \mu \mathrm{m}$ (magnification: 400X). NLB = natural latex biomembrane; $\mathrm{DL}=$ denatured latex; ePTFE = expanded polytetrafluorethylene; sham: without implant. In contrast to the other groups, the NLB and DL groups showed more pronounced blood vessel (arrows) formation on days 7 and 14 . 

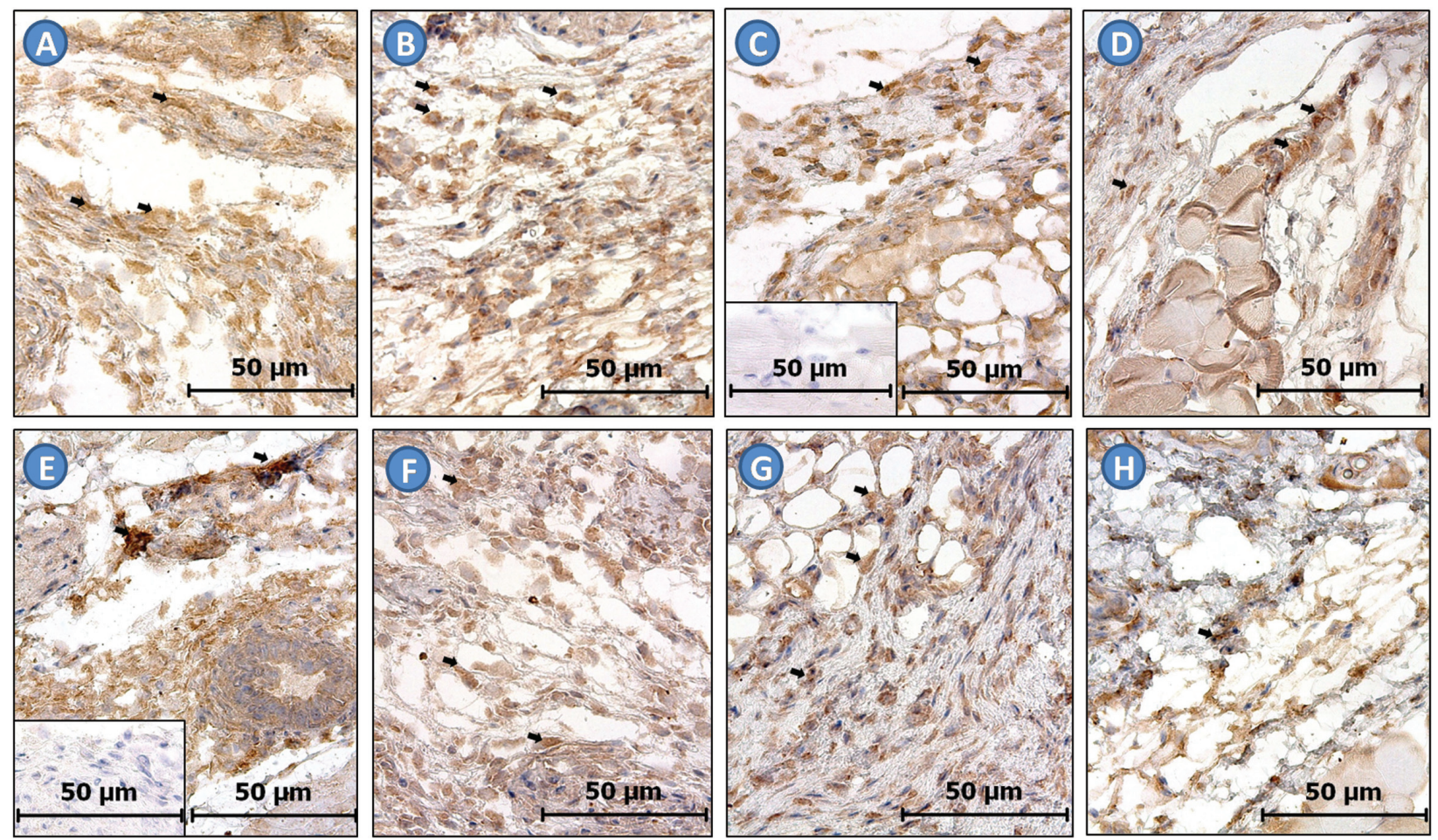

Figure 5. Immunohistochemical staining for vascular endothelial growth factor (VEGF) on the 7th (arrows; $A-D)$ and 14 th $(E-H)$ days of implantation in groups NLB $(A / E)$, DL $(B / F)$, ePTFE $(C / G)$, and sham $(D / H)$. Detail: negative control. Bar $=50 \mu \mathrm{m}(\mathrm{magnification:}$ 400X). NLB = natural latex biomembrane; $\mathrm{DL}=$ denatured latex; ePTFE = expanded polytetrafluorethylene; sham $=$ without implant. All implants showed low staining for VEGF. Thus, the mechanism of stimulation of blood vessel formation does not seem to be totally dependent on VEGF production.
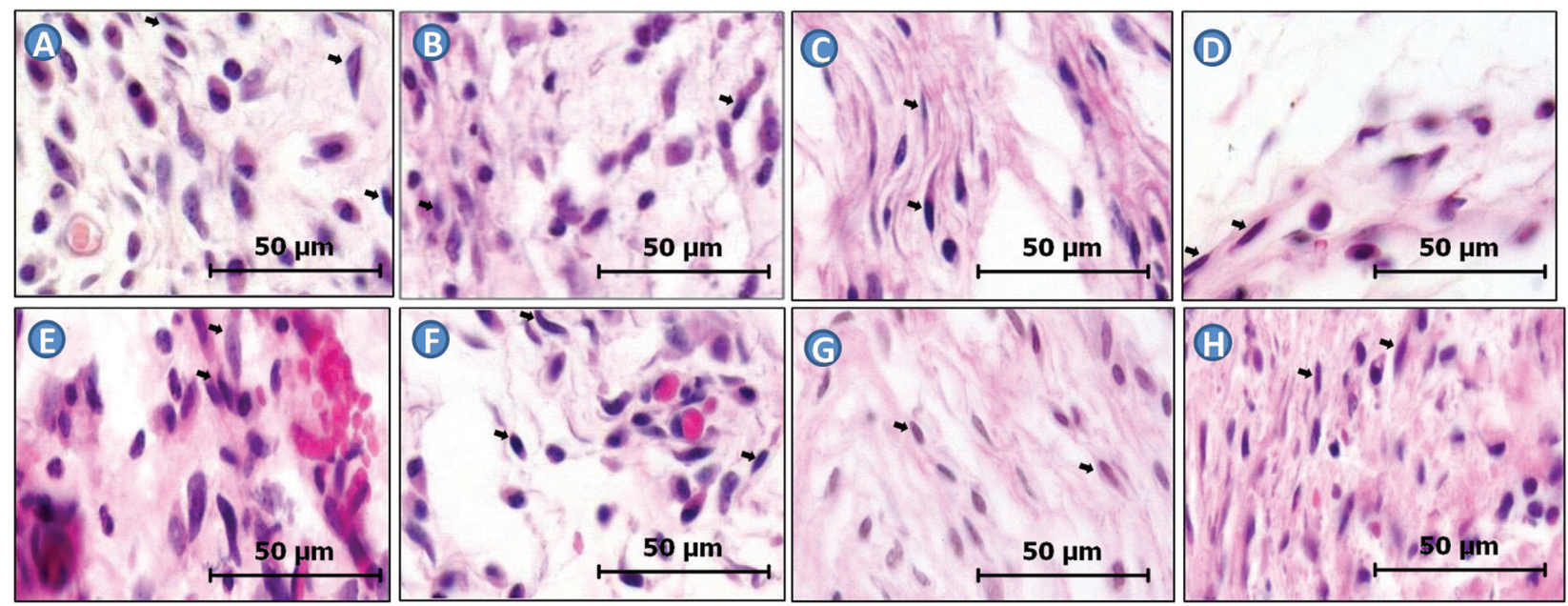

Figure 6. Histological alterations (HE) showing fibroplasia in groups NLB $(A / E)$, DL $(B / F)$, ePTFE $(C / G)$, and sham $(D / H)$, on the 7 th $(A-D)$ and 14th $(E-H)$ days. Bar $=50 \mu \mathrm{m}$ (magnification: 400X). NLB = natural latex biomembrane; DL = denatured latex; ePTFE: expanded polytetrafluorethylene; sham = without implant. On day 7, the ePTFE group showed more fibroblasts (arrows) compared to the other groups with a reduction occurring on day 14. The NLB and DL groups presented more pronounced fibroplasia on day 14. 


\section{Fibroplasia}

On day 7 , the NLB group showed an equal number of fibroblasts and inflammatory cells, while in the DL and sham groups the number of inflammatory cells was higher than that of fibroblasts. The ePTFE group showed a higher number of fibroblasts than of inflammatory cells (Figure 6A-D). On day 14 , the number of fibroblasts in the ePTFE and NLB groups was higher than the number of inflammatory cells in contrast to the DL and sham groups (Figure 6E-H).

All groups showed a significant improvement in fibroplasia from day 2 to day $7(P<0.05)$. The ePTFE group presented a higher level of fibroplasia than the DL group ( $P$ $<0.05)$, whereas the sham group showed lower fibroplasia than the NLB and DL groups $(P<0.05)$ on day 7 . However, no significant difference was observed between the NLB and DL groups. All groups presented a statistical increase from day 7 to day $14(P<0.05)$, except for the ePTFE group, which showed a decrease $(P<0.05)$. On day 14 , the NLB and DL groups showed higher fibroplasia than the ePTFE and sham groups $(\mathrm{P}<0.05$; Table 2$)$.

With respect to collagenesis, no statistical differences were observed between groups on day 2 . However, only the NLB and DL groups presented a significant improvement of collagenesis during follow-up $(P<0.05)$. On day 7 , the NLB and $\mathrm{DL}$ groups showed lower levels of collagen compared to the sham group $(P<0.05)$, whereas the ePTFE group showed higher levels compared to the $D L$ group $(P<0.05)$. On day 14, the ePTFE and sham groups showed a higher amount of collagen compared to the NLB and DL groups $(P<0.05$; Table 2).

Immunohistochemical staining showed higher expression of TGF- $\beta 1$ in the NLB group compared to the other groups on day 7 (Figure 7A-D), whereas on day 14, the level of TGF- $\beta 1$ expression decreased. This was in contrast to the ePTFE and sham groups, which showed higher expression of TGF- $\beta 1$ at this time (Figure 7E-H).

\section{Discussion}

The subcutaneous implant model has been shown to be appropriate to assess the potential of inducing tissue neoformation as reported by Kyriakides et al. (29). These investigators showed that this method of subcutaneous implantation is preferred for evaluation of the properties inherent to the implants, since it avoids the influence of additional factors such as microorganisms in models of
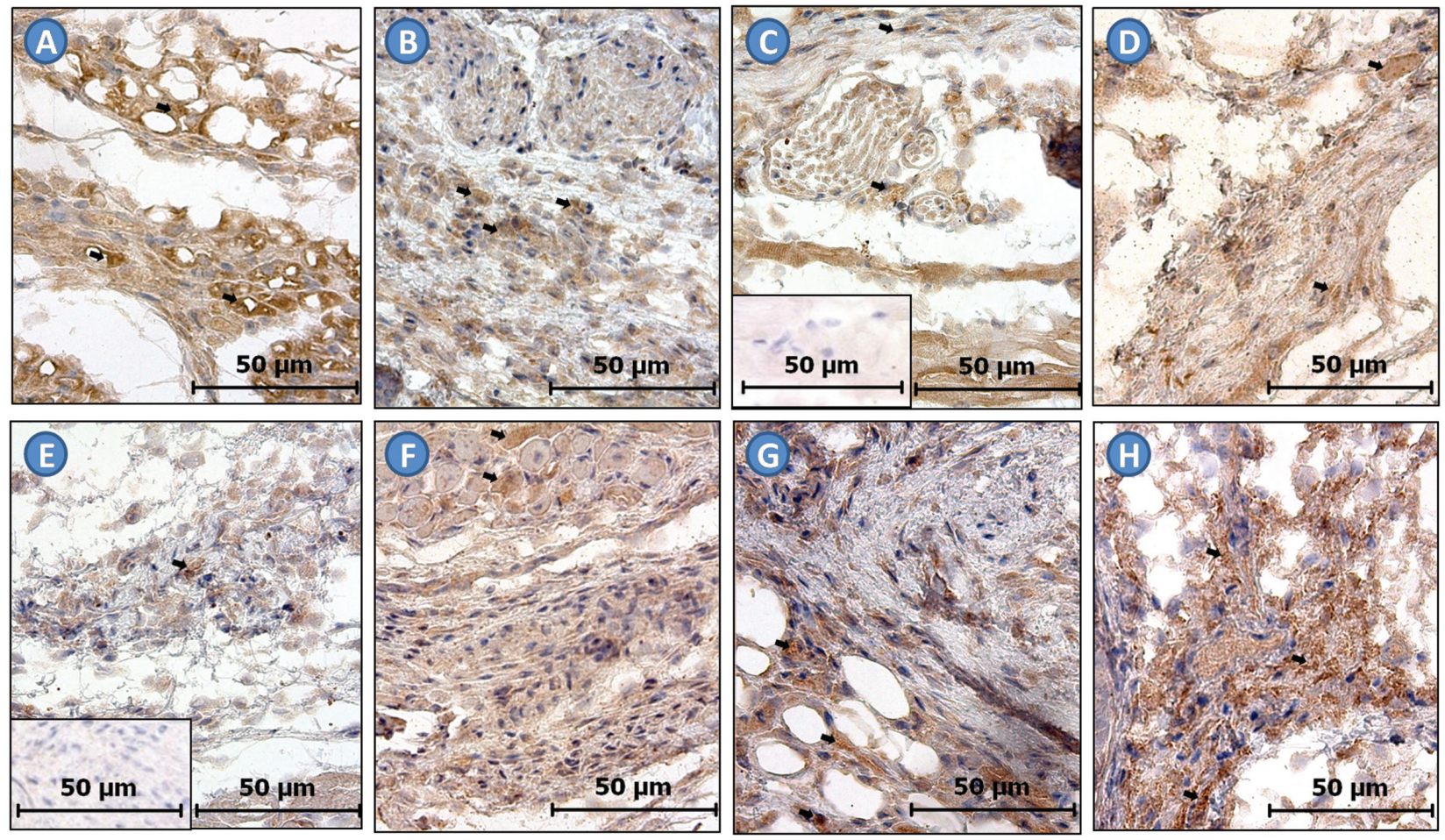

Figure 7. Immunohistochemical staining for transforming growth factor- $\beta 1$ (TGF- $\beta 1$ ) on the 7th (arrows) $(A-D)$ and 14 th $(E-H)$ days of implantation in groups NLB $(A / E)$, DL $(B / F)$, ePTFE $(C / G)$, and sham $(D / H)$. Detail: negative control. Bar $=50 \mu m$ (magnification: $400 X)$. $\mathrm{NLB}=$ natural latex biomembrane; $\mathrm{DL}=$ denatured latex; ePTFE = expanded polytetrafluorethylene; sham = without implant. The NLB group showed higher expression of TGF- $\beta 1$ compared to the other groups on day 7 . On day 14 , TGF- $\beta 1$ expression decreased in the NLB group and increased in the ePTFE and DL groups. 
open ulcer, which could change the wound healing process. Hence, subcutaneous implantation in a closed ulcer model was used to study the induction of tissue neoformation stimulated by NLB and other implants.

Neutrophils are the first cells to be activated in the host immune defense against infection. After tissue injury, these cells migrate to inflammatory loci, driven by chemotactic gradients, and recognize and phagocytize bacteria and necrotic tissue. Foreign pathogens are exposed to an arsenal of hydrolytic enzymes and bactericidal proteins pre-stored in the azurophilic granules of neutrophils, such as MPO, as well as generated ROS and RNS $(30,31)$. This status also results in the production of pro-inflammatory cytokines, such as IL-1 $\beta$, and stimulates iNOS to produce NO (30).

In the present study, NLB actively stimulated the inflammatory phase on the 2nd day after implantation as compared to other treatments and days $(P<0.05)$. This was demonstrated by the significantly increased number of inflammatory cells even in deep layers of the mouse skin, consisting largely of PMN in the NLB group (Figure 2; Table 2), which was also supported by the increased level of MPO (Table 1). DL stimulated the inflammatory phase more than ePTFE and sham treatment, but its action was not as high as that of NLB (Tables 1 and 2; Figure 2). Furthermore, the inflammatory infiltrate also showed similar induction of IL-1 $\beta$ in the NLB and sham groups. However, only limited induction of iNOS, another marker of inflammation, was observed in the present study (Figure 3).

These data seem to support the clinical findings of Frade et al. $(9,11)$ who reported the importance of the debridement activity induced by NLB in the healing of diabetic ulcers and pressure ulcers, respectively. In contrast to the NLB group, this inflammatory activity was not observed in the DL group suggesting the importance of the native protein(s) of latex in the healing process (12).

When NLB was studied in bladder augmentation in rabbits, Domingos et al. (14) showed that the inflammatory reaction was more intense on the 15th post-operative day and decreased significantly later on, which may be regarded as evidence of no rejection. This may be correlated to the NLB preparation, which preserves the native conformation of latex proteins by avoiding temperatures higher than $60^{\circ} \mathrm{C}$ during manufacture and hence latex vulcanization (14).

The highest inflammatory stimulus by NLB on day 2 was accompanied by a significant tissue augmentation observed only in the NLB group on day 2 and followed by tissue reduction during follow-up (Figure 1). This correlated with the highest level of total protein observed in the NLB group on day 2 (Table 1).

From day 2 to day 7, the NLB group showed a significant control of inflammatory activity by the reduction of MPO levels (Table 1) and a more pronounced amount of inflammatory infiltrate than in the other groups (Table 2). Arnhold (32) showed that MPO also modulates a variety of aspects of the inflammatory response. It is assumed that the MPO- $\mathrm{H}_{2} \mathrm{O}_{2}$-halide system inactivates some of the secreted granule content, decreases the binding of formylated peptides to chemotactic receptors, and influences other functions in stimulated PMNs (33). Thus, MPO contributes to the physiological feedback of PMN recruitment contributing to the reduction of PMN influx in inflammatory loci. This is supported by studies showing MPO-deficient PMNs, which usually exhibit a stronger and more prolonged respiratory burst $(34,35)$.

MPO is also involved in the formation of ROS and in the oxidation of biological material together with the membranous NADPH oxidase. MPO in the presence of $\mathrm{H}_{2} \mathrm{O}_{2}$ and $\mathrm{Cl}^{-}$generates hypochlorous acid $(\mathrm{HOCl})$, which oxidizes amino acids to chloramines. These derivatives lose $\mathrm{Cl}^{-}$and $\mathrm{CO}_{2}$ and produce imines, which are hydrolyzed to aldehydes such as MDA (32).

Thus, the higher the amount of inflammatory cells recruited to the site of injury, the higher the MPO and total protein levels. Thus, the amount of tissue neoformed in the NLB group on day 2 might be related to a higher oxidative stress status induced by MDA in the NLB group only on day 7 of follow-up. This status differed from the ePTFE group, which did not show considerable inflammatory activity on day 2 , nor a significant neoformed tissue as observed in the NLB group, but showed the highest MDA level on day 2. Regarding the DL group, the MDA level was similar to that of the sham group on days 2 and 7 , with a slight improvement on day 14. This difference between the NLB and DL groups might be related to the denaturated conformation of latex in the DL group.

The lowest FOX level in the NLB group during followup compared to other groups seemed to show that the mechanism of action of NLB on tissue induction is not dependent on a high amount of $\mathrm{H}_{2} \mathrm{O}_{2}$. These results were corroborated by the lowest levels of GSH in the NLB group, an antioxidant peptide, which has an important function as an electron donor when there is high production of $\mathrm{H}_{2} \mathrm{O}_{2}$ or lipid peroxidation.

Thus, the NLB seemed to induce inflammation and oxidative stress mediated mainly by MDA after day 2 of follow-up, important mechanisms for cell proliferation and tissue formation.

The importance of angiogenesis in wound healing is related to the supply of nutrients and oxygen to the neoformed tissue (36). The NLB implant stimulated significantly higher neoformation of blood vessels than sham, which was evident on day 7 of follow-up (Figure 4). On the other hand, the DL group showed decreased VEGF expression from day 7 to day 14 of follow-up whereas in the other groups the expression was not significantly changed during this period (Figure 5). The increased numbers of blood vessels in the NLB and DL groups on the 7th and 14th days and the absence of significant changes in the expression of VEGF in these groups suggest that angiogenesis might be related to previous inflammatory activity, triggered by the participation of neutrophils and/or macrophages. In 
this respect, Sisco et al. (37) proposed that the formation of granulation tissue involving fibroblast migration and proliferation, matrix deposition, and angiogenesis is driven by macrophage cytokine expression.

The ePTFE biomaterial was a stronger stimulator of fibroplasia compared to NLB, DL and sham on day 7. Collagen production did not differ among groups on day 2 of follow-up; however, the ePTFE and sham groups presented a significantly greater quantity of collagen on days 7 and 14 . Interestingly, although the ePTFE and sham groups showed increased collagen production in comparison to NLB, their numbers of fibroblasts were significantly lower than in the NLB group on day 14 (Figure 6; Table 2).

Collagen production can be stimulated by the expression of TGF- $\beta 1(38,39)$. However, immunohistochemical staining for TGF- $\beta 1$ showed a decrease in this cytokine on days 7 and 14 in the presence of NLB, whereas an increase was observed in the ePTFE and sham groups. The DL group showed low expression of TGF- $\beta 1$ throughout the period of follow-up (Figure 7). These data suggest that fibrogenesis stimulated by NLB cannot be directly related to TGF- $\beta 1$ levels. Corroborating these observations, Imamura et al. (40) reported the inhibition of fibrogenesis with suppression of macrophage infiltrate suggesting the importance of macrophages in the production of other essential factors for fibrogenesis, not only TGF- $\beta 1$. Sisco et al. (37) reported that the reduction in granulation tissue formation may reflect a disregulation of these macrophage-derived signals, which coordinate the function of dermal fibroblasts, keratinocytes,

\section{References}

1. Velnar T, Bailey T, Smrkolj V. The wound healing process: an overview of the cellular and molecular mechanisms. J Int Med Res 2009; 37: 1528-1542.

2. Gurtner GC, Werner S, Barrandon Y, Longaker MT. Wound repair and regeneration. Nature 2008; 453: 314-321.

3. Sen CK. The general case for redox control of wound repair. Wound Repair Regen 2003; 11: 431-438.

4. Ham J, Miller PJ. Expanded polytetrafluoroethylene implants in rhinoplasty: literature review, operative techniques, and outcome. Facial Plast Surg 2003; 19: 331-339.

5. Williams SK, Berman SS, Kleinert LB. Differential healing and neovascularization of ePTFE implants in subcutaneous versus adipose tissue. J Biomed Mater Res 1997; 35: 473481.

6. Campos PP, Andrade SP, Moro L, Ferreira MA, Vasconcelos AC. Cellular proliferation, differentiation and apoptosis in polyether-polyurethane sponge implant model in mice. Histol Histopathol 2006; 21: 1263-1270.

7. Mrué F, Coutinho-Netto J, Ceneviva R, Lachat JJ, Thomazini JA, Tambelini H. Evaluation of the biocompatibility of new biomembrane. Mat Res 2004; 7: 277-283.

8. Oliveira JA, Hyppolito MA, Coutinho-Netto J, Mrué F. Miringoplasia com a utilização de um novo material biossintético. Rev Bras Otorrinolaringol 2003; 69: 649-655. other immune-derived cells, or endothelial cells, explaining the importance of the inflammatory phase in the wound healing process.

In conclusion, the present study showed that the natural latex biomembrane from the rubber tree $H$. brasiliensis stimulates the stages of healing, especially the inflammatory phase by the recruitment of leukocytes to the site of injury, inducing important expression of $\mathrm{IL}-1 \beta$ and stimulating oxidative stress mainly by an increase of MPO, MDA and $\mathrm{H}_{2} \mathrm{O}_{2}$. These factors seem to be related to the strong angiogenesis (with low participation of VEGF) and fibroplasia (with low participation of TGF- $\beta 1$ ) stimulated by NLB in the cell proliferation and tissue formation phase. In contrast, the denaturation of latex in DL significantly delayed the inflammatory stimulus without interfering in the angiogenesis and fibroplasia phases. However, the ePTFE did not present interference in angiogenesis and showed a significant stimulus of fibroplasia and collagenesis.

\section{Acknowledgments}

Mrs. Marilena Heredia is acknowledged for histology technical support (Departamento de Patologia, Universidade de Ribeirão Preto) and MSc. Paula Payão Ovidio for oxidative stress technical support (Divisão de Nutrição e Metabolismo, Departamento de Clínica Médica, Faculdade de Medicina de Ribeirão Preto, USP). This study was supported financially by CAPES, FAEPA-HCFMRP/USP and CNPq/DECIT - Brazil.
9. Frade MA, Cursi IB, Andrade FF, Coutinho-Netto J, Barbetta FM, Foss NT. Management of diabetic skin wounds with a natural latex biomembrane. Med Cutan Iber Lat Am 2004; 32: 157-162.

10. Frade MA, Valverde RV, de Assis RV, Coutinho-Netto J, Foss NT. Chronic phlebopathic cutaneous ulcer: a therapeutic proposal. Int J Dermatol 2001; 40: 238-240.

11. Frade MA, Salathiel AM, Mazzucato EL, Coutinho-Netto J, Foss NT. A natural biomembrane as a new porposal for the treatment of pressure ulcers. Med Cutan Iber Lat Am 2006; 34: 137-142.

12. Pinho EC, Sousa SJ, Schaud F, Lachat JJ, Coutinho-Netto $J$. Experimental use of latex biomembrane in conjunctival reconstruction. Arq Bras Oftalmol 2004; 67: 27-32.

13. Balabanian CA, Coutinho-Netto J, Lamano-Carvalho TL, Lacerda SA, Brentegani LG. Biocompatibility of natural latex implanted into dental alveolus of rats. J Oral Sci 2006; 48: 201-205.

14. Domingos AL, Tucci S Jr, Garcia SB, de Bessa J Jr, Cologna AJ, Martins AC. Use of a latex biomembrane for bladder augmentation in a rabbit model: biocompatibility, clinical and histological outcomes. Int Braz J Urol 2009; 35: 217-224.

15. Sader SL, Coutinho-Netto J, Barbieri-Neto J, Mazzetto SA, Alves-Jr P, Vanni JC, et al. Substituição parcial do pericár- 
dio de cães por membrana de látex natural. Rev Bras Cir Cardiovasc 2000; 15: 338-344.

16. Paulo NM, Lima FG, Siqueira Junior JT, Fleury LF, Sant'Ana FJ, Borges AC, et al. [Seringueira's latex membrane (Hevea brasiliensis) with and without polylysine $0.1 \%$ and marlex mesh for the reconstruction of iatrogenics abdominal wall defects in rats]. Acta Cir Bras 2005; 20: 305-310.

17. Frade MA, Coutinho-Netto J, Gomes FG, Mazzucato EL, Andrade TA, Foss NT. Curativo de biomembrana vegetal (BMV) e hipersensibilidade. An Bras Dermatol 2011 (in press).

18. Rolland JM, O'Hehir RE. Latex allergy: a model for therapy. Clin Exp Allergy 2008; 38: 898-912.

19. Frade MA, de Assis RV, Coutinho-Netto J, Andrade TA, Foss NT. Biomembrana vegetal na cicatrização de úlceras venosas crônicas. An Bras Dermatol 2012 (in press).

20. Chotigeat W, Duangchu S, Wititsuwannakun R, Phongdara A. Cloning and characterization of pectate lyase from Hevea brasiliensis. Plant Physiol Biochem 2009; 47: 243-247.

21. Buege JA, Aust SD. Microsomal lipid peroxidation. Methods Enzymol 1978; 52: 302-310.

22. Esterbauer H, Cheeseman KH. Determination of aldehydic lipid peroxidation products: malonaldehyde and 4-hydroxynonenal. Methods Enzymol 1990; 186: 407-421.

23. Souza DG, Cassali GD, Poole S, Teixeira MM. Effects of inhibition of PDE4 and TNF-alpha on local and remote injuries following ischaemia and reperfusion injury. $\mathrm{Br} J$ Pharmacol 2001; 134: 985-994.

24. Tomruk A, Guler G, Dincel AS. The influence of $1800 \mathrm{MHz}$ GSM-like signals on hepatic oxidative DNA and lipid damage in nonpregnant, pregnant, and newly born rabbits. Cell Biochem Biophys 2010; 56: 39-47.

25. Sedlak J, Lindsay RH. Estimation of total, protein-bound, and nonprotein sulfhydryl groups in tissue with Ellman's reagent. Anal Biochem 1968; 25: 192-205.

26. Caetano KS, Frade MA, Minatel DG, Santana LA, Enwemeka CS. Phototherapy improves healing of chronic venous ulcers. Photomed Laser Surg 2009; 27: 111-118.

27. Noursadeghi M, Tsang J, Haustein T, Miller RF, Chain BM, Katz DR. Quantitative imaging assay for NF-kB nuclear translocation in primary human macrophages. $\mathrm{J}$ Immunol Methods 2008; 329: 194-200.

28. Carvalho PT, Mazzer N, dos Reis FA, Belchior AC, Silva IS. Analysis of the influence of low-power HeNe laser on the healing of skin wounds in diabetic and non-diabetic rats. Acta Cir Bras 2006; 21: 177-183.

29. Kyriakides TR, Zhu YH, Yang Z, Huynh G, Bornstein P. Altered extracellular matrix remodeling and angiogenesis in sponge granulomas of thrombospondin 2-null mice. Am J Pathol 2001; 159: 1255-1262.

30. Sherwood ER, Toliver-Kinsky T. Mechanisms of the inflammatory response. Best Pract Res Clin Anaesthesiol 2004; 18: 385-405.

31. Fantone JC, Ward PA. Role of oxygen-derived free radicals and metabolites in leukocyte-dependent inflammatory reactions. Am J Pathol 1982; 107: 395-418.

32. Arnhold J. Properties, functions, and secretion of human myeloperoxidase. Biochemistry 2004; 69: 4-9.

33. Nauseef WM. Myeloperoxidase deficiency. Hematol Oncol Clin North Am 1988; 2: 135-158.

34. Rosen H, Klebanoff SJ. Chemiluminescence and superoxide production by myeloperoxidase-deficient leukocytes. J Clin Invest 1976; 58: 50-60.

35. Stendahl O, Coble BI, Dahlgren C, Hed J, Molin L. Myeloperoxidase modulates the phagocytic activity of polymorphonuclear neutrophil leukocytes. Studies with cells from a myeloperoxidase-deficient patient. J Clin Invest 1984; 73: 366-373.

36. Bates DO, Jones RO. The role of vascular endothelial growth factor in wound healing. Int J Low Extrem Wounds 2003; 2: 107-120.

37. Sisco M, Chao JD, Kim I, Mogford JE, Mayadas TN, Mustoe TA. Delayed wound healing in Mac-1-deficient mice is associated with normal monocyte recruitment. Wound Repair Regen 2007; 15: 566-571.

38. Stadelmann WK, Digenis AG, Tobin GR. Physiology and healing dynamics of chronic cutaneous wounds. Am J Surg 1998; 176: 26S-38S.

39. Cheng B, Fu X, Sheng Z, Gu X, Sun T, Sun X. [The effect of basic fibroblast growth factor on myofibroblasts and its significance on wound healing]. Zhonghua Yi Xue Za Zhi 2002; 82: 1187-1191.

40. Imamura M, Ogawa T, Sasaguri Y, Chayama K, Ueno H. Suppression of macrophage infiltration inhibits activation of hepatic stellate cells and liver fibrogenesis in rats. Gastroenterology 2005; 128: 138-146. 